\title{
Impact of a policy of direct admission to a coronary care unit on use of thrombolytic treatment
}

\author{
J M A BURNS, * K J HOGG, $†$ A P RAE, * W S HILlis, † F G DUNN* \\ From the Departments of ${ }^{\star}$ Cardiology and $\dagger$ Materia Medica, Stobhill General Hospital, Glasgow
}

SUMMARY Because thrombolytic treatment is effective only if it is given within six hours of acute myocardial infarction it is vital to admit patients to the coronary care unit as soon as possible after the acute event. A policy of admitting patients directly to the coronary care unit at the request of the patient's general practitioner by a telephone line that is independent of the hospital switchboard significantly reduced the delay. Those admitted via the accident and emergency department at the $N$ same hospital reached the coronary care unit $1 \mathrm{~h} 32 \mathrm{~min}$ after the onset of chest pain whereas the 100 의 patients admitted directly took only 43 minutes. The policy of direct admission also significantly increased both the percentage of patients who received thrombolytic treatment and the percentage of patients admitted within three hours from the onset of symptoms.

The value of thrombolytic treatment in acute myocardial infarction is well established. ${ }^{12}$ The improvement in left ventricular function and the reduction in mortality were greatest with early thrombolytic treatment. ${ }^{1-3}$ Thrombolysis should be attempted as soon as possible after infarction. ${ }^{4}$

We assessed a method for reducing delay in admission to the coronary care unit and what effect this might have on the number of patients suitable for thrombolytic treatment.

\section{Patients and methods}

Since 1976 there has been a policy of direct admission to the coronary care unit at Stobhill Hospital, but the extent to which it has been used varied. We discussed this at a clinical meeting with local general practitioners, and identified several difficulties including delay in contacting medical staff via the hospital switchboard at busy times, and the preference of the junior medical staff to "screen" patients within the accident and emergency department rather than in the coronary care unit. In an attempt to reduce the delay of admission to the coronary care unit, we installed a telephone (with a number independent of the hospital switchboard) in the coronary care unit so that the nursing staff could accept for assessment any patients in whom the general practitioner suspected

Requests for reprints to Dr F G Dunn, Department of Cardiology, Stobhill General Hospital, Glasgow G21 3UW.

Accepted for publication 8 December 1988 an acute myocardial infarction. We wrote to the general practitioners to explain the rationale for early referral and to tell them about the direct telephone line. We encouraged general practitioners to refer all patients with chest pain that might be caused by an acute myocardial infarction.

The procedure room at the back of the coronary care unit has a door into the hospital car park, which gives easy access for ambulances. If the procedure room is in use when a patient arrives at the coronary care unit the patient can be brought in through the front door of the coronary care unit into one of the beds in the unit. Although we expected some congestion at times, this was rare, and two patients never arrived together at the back door. The patients were assessed in the procedure room and the receiving medical registrar decided whether the patient should be kept in the coronary care unit, admitted to one of the general medical wards, or sent home.

We studied all patients who were referred in the first six months of the telephone system-that is from April 1987. In addition, we compared a subset of these patients who were admitted within six hours of the onset of symptoms with a second group, who despite the new system were referred to the accident and emergency department. Self referrals were not included in the analysis. We chose six hours because this is the cut off point in our unit for administration of thrombolytic treatment. We give thrombolytic treatment to all patients under the age of 70 with electrocardiographic evidence of acute myocardial infarction in whom there are no established contraindications. 
At admission we noted the elements that accounted for the delay before thrombolysis. These were: the time from onset of symptoms until the general practitioner was contacted; the time taken by the general practitioner to arrive at the patient's home; the interval between the arrival of the general practitioner and the admission of the patient to the coronary care unit. Because the benefits of thrombolytic treatment are greatest the earlier it is administered, we also looked at the number of patients admitted within three hours of the onset of symptoms in both groups.

We compared the time differences between the two groups by a Mann-Whitney $U$ test and the difference in numbers receiving thrombolytic treatment by $\chi^{2}$ analysis.

\section{Results}

There was a steady decline in the use of the direct telephone line after the first month. So at the end of the third month we sent a second letter with a label with the telephone number on it. After this, use of the telephone line again increased. A total of 100 patients were referred via this system and 65 were kept in the coronary care unit. Thirty seven of the 65 were subsequently found to have had an acute myocardial infarction. Of the remaining 35 patients, 30 were transferred to the general medical wards, three were discharged home, and two were diverted to another hospital en route. Of the 30 patients transferred to the general medical wards, six had a discharge diagnosis of acute myocardial infarction, seven of unstable angina, eight of chest pain of uncertain cause, three of cardiac failure, two of syncope of uncertain cause, two of pneumonia, and one each of pulmonary embolism and cholecystitis. Review of the discharge records of these patients showed that hospital admission was required in each case, and therefore it appeared that the direct admission policy did not result in unnecessary admissions. Of the 65 patients admitted directly to the coronary care unit, 55 had pain lasting less than six hours, and we compared this group with 32 patients admitted from the accident and emergency department over the same period.

Figure 1 shows the various components of delay in admission. A major component was the interval from the onset of symptoms until the general practitioner was contacted, and this was similar in patients admitted directly to the coronary care unit and in those admitted to the accident and emergency department. Nor was there any significant difference between the groups in the time taken for the general practitioner to arrive. There was, however, a significant difference between the interval from the arrival of the general practitioner and subsequent admission to the coronary care unit. In patients admitted via the accident and emergency department, the mean time to admission was 1 hour and 32 minutes (range 25 minutes to 3 hours 40 minutes) and in the group admitted directly to the coronary care unit the mean time was 43 minutes (range 5 minutes to 2 hours) (p $<0.001)$.

The percentages of patients in whom acute myocardial infarction was confirmed were similar in the two groups $(19(59 \%)$ in the accident and emergency group and $31(56 \%)$ in the direct admission group). A similar pattern of delay was seen in patients with acute myocardial infarction, with reduction from 1 hour 25 minutes (range 25 minutes to 3 hours 50 minutes) in the accident and emergency group to 41 minutes (range five minutes to one hour 40 minutes) in the directly referred group ( $p<$ 0.001 ).

Of the patients with acute myocardial infarction, 15 of the 31 admitted directly to the coronary care unit received thrombolytic treatment compared with three out of 19 in the accident and emergency group
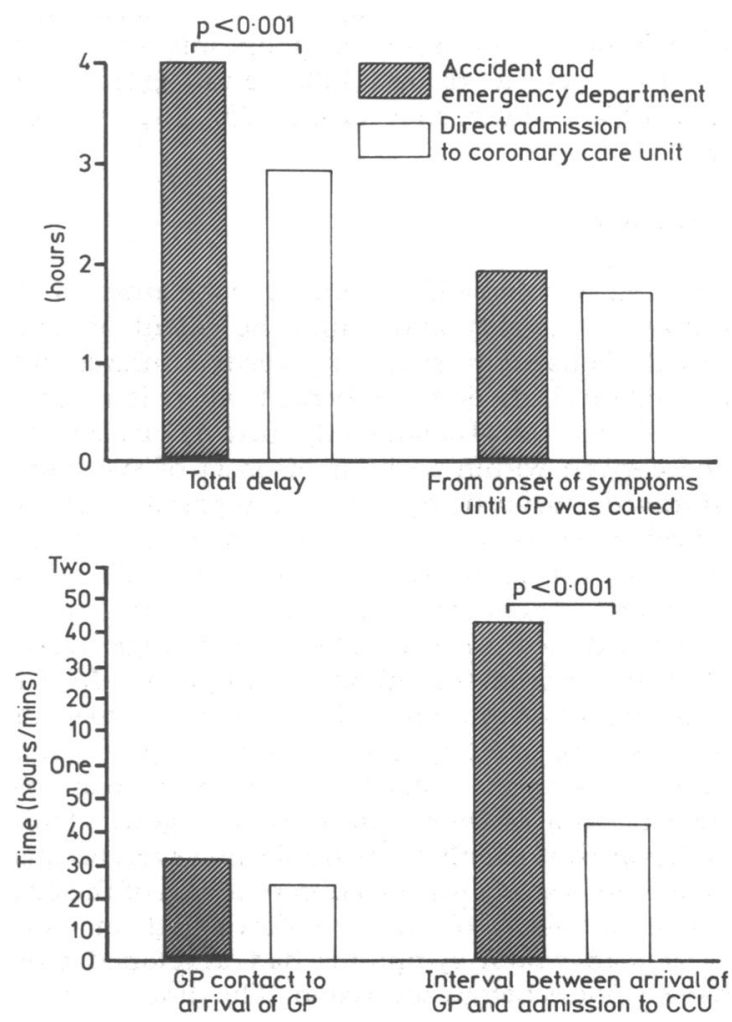

Fig 1 Delay of patients admitted to the coronary care unit within six hours of the onset of chest pain by either the direct telephone route or via the accident and emergency department. 
Admitted within 3hours

Receiving thrombolytic treatment

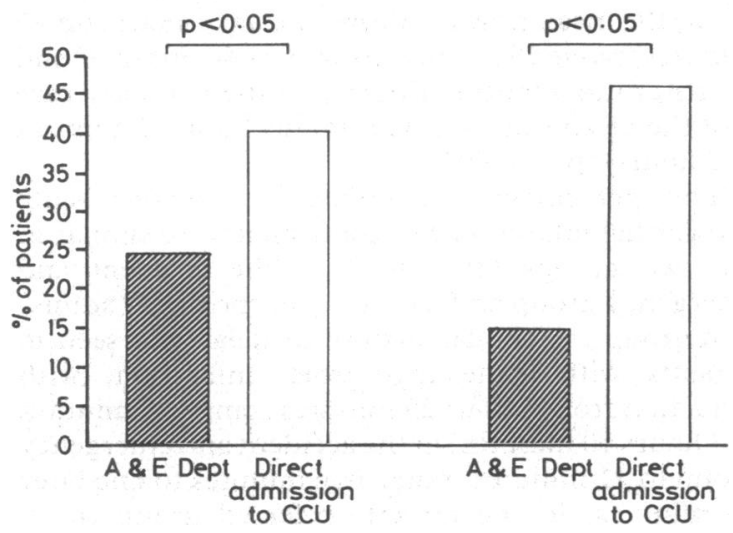

Fig 2 Percentage of patients in each group who were admitted within three hours of the onset of symptoms and percentage of those with myocardial infarction who received thrombolytic treatment.

$(p<0.05)$. A total of 31 patients (13 of whom received thrombolytic therapy) were admitted within three hours of the onset of symptoms-23 in the directly referred group $(42 \%)$ and eight in the accident and emergency group $(25 \%)(p<0.05$, fig 2).

\section{Discussion}

Early intervention with thrombolytic treatment both improves mortality and limits the extent of myocardial damage in acute myocardial infarction. ${ }^{12}$ Thrombolysis is of most benefit when it is given early. Thus in an Italian study intravenous streptokinase given within an hour of onset of symptoms improved survival by $46 \%$ compared with an improvement of $17 \%$ in the treatment group as a whole. ${ }^{1}$ This reinforces the need to look at the different components of the delay before the start of specialised medical help. The biggest single reason for exclusion from thrombolytic treatment is delay in reporting of symptoms. ${ }^{3}$ We confirmed that the major source of delay is in the reporting of symptoms. This seems considerably shorter than that reported in a previous study for Glasgow. ${ }^{5}$ These studies are not strictly comparable, however, because the previous study was in a different area of the city, was undertaken 10 years before, and included patients in whom symptoms had developed more than six hours before admission. The time to reporting of symptoms remains the major source of delay, but it is doubtful whether much impact can be made on this. Public education programmes could be considered, but it is unlikely this will modify what is often an instinctive pattern of behaviour. ${ }^{6}$ Also we doubt whether the time taken by the general practitioner to arrive at the patient's home can be reduced. General practitioners have been equipped with defibrillators in an attempt to bring coronary care to the patient at an earlier stage. ${ }^{7}$ But 18 months afterwards only $57 \%$ were still carrying their defibrillators regularly while on call. ${ }^{8}$ Thrombolytic treatment might be given by general practitioners or the ambulance crew. Mobile coronary care units are successfully used in Belfast, ${ }^{9}$ and may provide the best way of administering thrombolytic treatment in the community. The administration of thrombolytic treatment in the community is being assessed. ${ }^{10}$

At present most patients admitted with acute myocardial infarction are first referred to the accident and emergency department, which is often an unsatisfactory place for the immediate management of such patients. ${ }^{4}$ They are generally seen, first by junior house officers, who may be slow to diagnose an infarct and to offer effective pain relief. Direct referral of patients to the coronary care units not only reduces the delay but it also leads to the patients being treated more quickly and efficiently by medical and nursing staff trained in coronary care.

We encountered few practical problems when patients were referred directly to the coronary care unit. All patients were fully assessed in the reception area in coronary care unit and were then admitted to the coronary care unit or to one of the medical wards as appropriate. Occasionally the patient was sent home $(2 \%$ of the total number of referrals). Thirty seven of the total of 100 directly referred patients were subsequently shown to have acute myocardial infarction. The main problem with this policy is the need to keep reinforcing its use by the local general practitioners, because over the months enthusiasm wanes. ${ }^{8}$

The key aspect of such a method of reducing delay is its effect on the numbers of patients who are suitable for thrombolytic treatment. We found a significant increase in the number of patients admitted within three hours of the onset of symptoms when benefit from thrombolytic treatment is greatest, and also in those who received thrombolytic therapy on admission to the coronary care unit. The differences in the numbers who received thrombolytic treatment indicate that the recruitment rate for this treatment can be enhanced by a policy of direct admission to the coronary care unit.

The major delay in patients with acute myocardial infarction remains in the reporting of symptoms. Referral via the accident and emergency department is a major source of avoidable delay that can be eliminated by a policy of direct admission. This policy significantly reduced the delay in admission to 
the coronary care unit and increased the proportion of patients who were suitable for and most likely to benefit from thrombolytic treatment.

\section{References}

1 Gruppo Italiano per lo Studio della Streptocochinasi Nell' Infarcto Miocardio (GISSI). Effectiveness of thrombolytic therapy. Lancet 1986;i:397-402.

2 Simoons ML, Serruys PW, Van der Brand M, et al. Early thrombolysis in acute myocardial infarction: limitation of infarct size and improved survival. $\mathrm{J} \mathrm{Am}$ Coll Cardiol 1986;7:717-28.

3 Jagger JD, Murray RG, Davies MK, Littler WA, Flint EJ. Eligibility for thrombolytic therapy in acute yocardial infarction. Lancet 1987;i:34-5.

4 Julian DG, Pentecost BL, Chamberlain DA. A milestone for myocardial infarction. $\mathrm{Br} M e d \mathrm{~J}$ 1988;297:497-8.
5 Dunn FG, Elms S, Melville DI, Lawrie TDV, Murray TS. Early treatment of myocardial infarction in the community. Br Med J 1978;ii:1143-5.

6 Rawles JM, Haites NE. Patient and general practitioner delays in acute myocardial infarction. $\mathrm{Br}$ Med J 1988;296:882-5.

7 Pai GR, Haites NE, Rawles JM. One thousand heart attacks in Grampian: the place of cardiopulmonary resuscitation in general practice. $\mathrm{Br}$ Med J 1987;294:352-4.

8 Rawles JM. General practitioners' management of acute myocardial infarction and cardiac arrest: relevance to thrombolytic therapy. $\mathrm{Br} M e d J$ 1987;295:639-40.

9 Pantridge JF, Geddes JS. A mobile coronary care unit in the management of myocardial infarction. Lancet 1967;ii:271-3.

10 Weiss AT, Fine FG, Applebaum D, et al. Pre-hospital coronary thrombolysis: a new strategy in acute myocardial infarction. Chest 1987;92:124-8. 


\section{Notices}

\section{British Cardiac Society}

The Annual General Meeting will take place in Torquay on 22 to 25 May 1990.

\section{Nuclear cardiology}

The British Nuclear Cardiology Group is holding a meeting in the Lecture Theatre of the National Heart and Lung Institute, Dovehouse Street, London SW3 on 3 November 1989. Further informaton: Dr Ann Tweddel, Department of Medical Cardiology, Royal Infirmary, 10 Alexandra Parade, Glasgow G31 2ER.

\section{Cardiac radiology}

The Bristol Cardiac Radiology Course is an intensive one day meeting to update radiologists and others interested in the imaging of the heart in all aspects of cardiac imaging. It will be held on 18 November 1989. For further information contact Dr G G Hartnell, Department of Radiodiagnosis, Bristol Royal Infirmary, Bristol BS2 8HW. Telephone 0272-230000 Ext 2130.

\section{Cardiology for the clinician}

A course on Cardiology '90-Pearls for the Clinician will be held in La Jolla, California on 25 to 27 January 1990. For further information write to Nancy Donegan, Deverman and Associates, 7777 Alvarado Road, Suite 110, La Mesa, California 92041, USA.

\section{Intensive care and emergency medicine}

The 10th International Symposium on Intensive Care and Emergency Medicine will be held in Brussels on 27 to 30 March 1990. For further information write to Professor J L Vincent, Department of Intensive Care, Erasme University Hospital, Route de Lennik 808, B-1070 Brussels, Belgium.

\section{Electrocardiology and vectorcardiography}

The XVII International Congress on Electrocardiology and XXXI International Symposium on Vectorcardiography will be held in Florence on 27 to 29 September 1990 . Information from the Organising Secretariat, Via G Modena 19, 50121 Florence, Italy.

\section{Correction}

Impact of a policy of direct admission to a coronary care unit on use of thrombolytic treatment $J M A$ Burns, K J Hogg, A P Rae, W S Hillis, F G DunnWe regret that there is an error in this article published in the April issue (volume 61: pages 322-5). In the Summary, the third sentence should have read "Those admitted via the accident and emergency department at the same hospital reached the coronary care unit $1 \mathrm{~h} 32 \mathrm{~min}$ after being seen by the general practitioner whereas the patients admitted directly took only 43 minutes". 